\section{Zdravko Saveski | \\ One in Seven and a Half: Local Activism against the Global Climate Crisis}

Bionote: Zdravko Saveski (1976), PhD in Political Science, is a researcher at the Institute of Social Sciences and Humanities - Skopje. He is author of Democracy: Models and Dilemmas (2011) and Beyond Uniform Thinking: Rediscovery of the Left (2006), co-author of several books including No pasarán: Participation of Fighters from Macedonia in the Spanish Civil War (2016) and Nationalism In/ Inside Context: Cooperation of Albanians and Macedonians from the Ilinden Uprising until the People's Liberation War (2014), and editor of Strike: Experiences and Actualities (2011) (all in Macedonian).

Institute of Social Sciences and Humanities - Skopje zdravko.saveski@isshs.edu.mk

Abstract: The climate crisis has become not only serious but urgent problem too. A lot of years have been wasted in palliative measures that have not solved the problems. And those wasted years have closed the space to search for solutions inside the framework of some kind of Green capitalism. At the present time, solutions to the climate crisis are still possible, but they will require drastic, even systematic measures. This article analyzes the role of capitalism in creating and deepening climate crisis. Capitalism is not only a type of economy but a type of society. It has achieved hegemony in the field of ideas and values, socializing people and internalizing its values among the losers of the system, as well as among its beneficiaries. Due to this, overcoming capitalism is not an easy or simple task. However, as it is argued in the article, the only humane alternative to overcome climate crisis is to overcome capitalism as a type of economy and a type of society.

Keywords: climate crisis, capitalism, system change

\section{Introduction}

As the climate crisis accelerates faster than expected, ${ }^{1}$ an increased number of people from across the globe are growing concerned about its effects and realizing that something has to be done. ${ }^{2}$ With the majority of people continuing down the path of business as usual, and governments acting as if they are "actually" doing something, calls for action are mounting by scientists and activists. The urgency of the moment is illustrated by Greta Thunberg's diagnosis that it is time to "start panicking about climate change," ${ }^{3}$ and David Attenborough's conclusion: "We cannot be radical enough."

What can and should be done? In countries like North Macedonia, where people are acutely disappointed by politics, where nihilism reigns, it is very difficult to motivate them to take action on any issue, including the climate crisis. This inactivity is further reinforced by the realization that this is an issue that should be tackled globally, that the contributions of big industrial countries are far more crucial and that actions taken by politicians and corporation owners can affect far bigger change than the actions of single individuals. After all, there are more than 7.5 billion people living on the planet, surely what an ordinary person does in his/her everyday life is irrelevant from the standpoint of preventing the climate crisis from escalating. It is easy to fall into the trap of this atomistic, pessimistic and demobilizing way of thinking. However, such views ignore some basic facts. First, when a single person begins to act, they are far from being alone in a world of 7.5 billion passive people. Many dozens or even hundreds of millions of people are already taking, at the very least, modest action in this global struggle with huge environmental and societal repercussions. So, when someone begins to act, it is far from being an isolated act. Even when the passivity of people in their immediate circles creates the illusion that they act alone.

\footnotetext{
William J. Ripple et al., "World Scientists' Warning of a Climate Emergency," BioScience, bizo88 (November 5, 2019). https://doi.org/10.1093/biosci/bizo88.

2 Sandra Laville and Jonathan Watts, "Across the Globe, Millions Join Biggest Climate Protest Ever," The Guardian (September 21, 2019). https://www.theguardian.com/environment/2019/ sep/21/across-the-globe-millions-join-biggest-climate-protest-ever.

${ }^{3}$ Sam Morgan, "Greta Thunberg Urges MEPs to 'Panic Like the House Is on Fire,"' Euractiv (April 16, 2019). https://www.euractiv.com/section/climate-environment/news/greta-thunberg-urgesmeps-to-panic-like-the-house-is-on-fire.

4 Adam Vaughan, "David Attenborough On Climate Change: 'We Cannot Be Radical Enough,"' New Scientist (July 9, 2019). https://www.newscientist.com/article/2209126-david-attenborough-on-climate-change-we-cannot-be-radical-enough.
} 
When someone starts to act, s/he joins the ranks of the millions of people who already act, dedicating their time, energy, and, in some cases, their lives to the struggle. S/he becomes one of the millions of active people with his/her efforts adding to their efforts. Realization of this fact should be inspiring, no matter how overwhelming the passivity and conservatism in the immediate circle of the concrete person is.

The second important point is the necessity of keeping in mind that the number of countries in the world is much smaller than the number of people living on the planet. Accordingly, while a single person is only one in 7.5 billion, a single country is one amongst two hundred. Why is it important to keep this proportion in mind? If changes are implemented on the national level, they can still amount to relatively minor contributions, which are nonetheless still much bigger than the contributions of a single person. A country that implements measures combating the climate crisis can be an inspiring example for the rest to follow (as Bhutan has already done) ${ }^{5}$ and can act together with other countries to press for more international and meaningful action. Therefore, pressing your own government to act in a responsible way concerning the climate crisis can enhance the effects of the efforts of single persons, no matter how small and "insignificant" the country we are talking about is.

This leads us to our third important point. A person aware of the climate crisis can and should act on a personal level, but s/he also must join forces with other people in pressing for and implementing the measures needed to solve the climate crisis. Collective action has a multiplying effect - it is much more potent than individual action alone. The effects of a number of individuals acting together are greater than the effects of the same number of individuals acting in isolation from each other. Common actions help overcome our sense of individual alienation and aid in the building of communities. This is crucial if the societal roots of the environmental crisis are to be addressed. And they need to be addressed, if substantial measures against climate crisis are to be implemented.

${ }_{5}$ Tyler Protano-Goodwin, "Bhutan Is the Only Carbon Negative Country in the World," GVI (May 2019). https://www.gvi.co.uk/blog/bhutan-carbon-negative-country-world.

\section{The Dynamics of a Crisis}

The issue that we deal with here is (still) mostly known as "climate change." However, this phrase has a euphemistic tone which in itself serves to delude people into thinking that climate change is not a pressing issue. In order to get the message through to people that the problem is very serious and urgent, a change in terminology is being implemented by many activists and media outlets, who talk about "climate crisis" instead of "climate change." As the UK Guardian has explained regarding this shift in their 2019 environmental pledge:

We will use language that recognizes the severity of the crisis we're in. In May 2019, the Guardian updated its style guide to introduce terms that more accurately describe the environmental crises facing the world, using "climate emergency, crisis or breakdown" and "global heating" instead of "climate change" and "global warming." We want to ensure that we are being scientifically precise, while also communicating clearly with readers on the urgency of this issue. ${ }^{6}$

There are significant changes happening in the climate and they have already reached crisis levels. It is crucial not to avoid this awareness, both in language and in reality. Since words influence thoughts, and not only the other way around.

In order to understand the climate crisis better, it is important to keep in mind what the crisis as a phenomenon is. Crises are non-routine events or series of events that shake up the current state of affairs and create high levels of instability and uncertainty. ${ }^{7}$ In most cases they come as unexpected, with little or no warning; the elements leading to a crisis, however, can be latently building for some time. During times of crisis, business as usual is no longer possible. It creates a dynamic state of affairs full of risks, threats and dangers but also simultaneously creates opportunities not otherwise open in regular, non-crisis times. Due to these features, crises are periods

\footnotetext{
6 "The Guardian Environmental Pledge," The Guardian (October 15, 2019). https://www. theguardian.com/environment/ng-interactive/2019/oct/16/the-guardians-climate-pledge-2019. See M. W. Seeger, T. L. Sellnow and R. R. Ulmer, "Communication, Organization, and Crisis," Communication Yearbook, Vol. 21 (1998), 231-75
} 
in which power and resources are redistributed either upwards or downwards. As for the effects of a crisis, they can either be reversible and repairable or irreversible and irreparable.

The climate crisis is such type of crisis that is characterized by long latent phase. The temperature is rising slowly, the rain is precipitating slowly, the ice is melting slowly. Sometimes things are getting more pronounced, hurricanes become more frequent and drastic, droughts more severe than before, but the pace of the crisis is still generally so slow that it, if not carefully observed, can easily be considered as a natural phenomenon, having little to no human impact. Even though it can be easily underestimated because of its relatively non-drastic effects during its latent phase, it needs only to deepen a little bit more, before it will have extreme and catastrophic environmental and societal repercussions, with cascading and irreversible effects. And the "zero hour," after which little can be done to reverse the effects of climate change, is quickly approaching. As António Guterres, Secretary-General of the United Nations has stressed, citing the warning from the Intergovernmental Panel on Climate Change's 2018 Special Report, humankind has only 11 years to avoid potentially irreversible climate disruption. ${ }^{8}$ This means that we are living in historic times, with our generation being the last generation that can prevent irreparable damage arising from the climate crisis. If we fail our task, if we become aware of how serious the problem really is only after its effects become irreversible, then lamenting the wasted opportunities will be worth nothing. To give only one example, if Greenland's ice melts, the sea level will rise by seven meters, ${ }^{9}$ and there will be no way to repair the damage. When it is gone, the ice cannot be recreated anew. The only way to avoid the consequences and cascading effects of Greenland's ice melt is to reverse policies and practices as quickly as possible. As for the consequences, it is also important to keep in mind that they will not be distributed evenly. The poor and global South will suffer the worst hit.

As with any other crisis, the climate crisis will lead to the redistribution of power and resources. Also, as with any other crisis, the climate crisis will open opportunities that are absent in regular,

8 "Only 11 Years Left to Prevent Irreversible Damage from Climate Change, Speakers Warn during General Assembly High-Level Meeting," United Nations (March 28, 2019). https://www. un.org/press/en/2019/ga12131.doc.htm.

9 Stephen Leahy, "Greenland's Ice Is Melting Four Times Faster Than Thought - What It Means," National Geographic (January 21, 2019). https://www.nationalgeographic.com/environment/2019/01/greeland-ice-melting-four-times-faster-than-thought-raising-sea-level. non-crisis times. The Great Recession one decade ago is a useful reminder. The crisis created by unrestrained capitalism has led to an even bigger concentration of capital in the hands of a few. Those who were responsible for the crisis benefited the most from it. Such outcomes are always a possibility when crises happen. The current situation with the climate crisis will also lead to the redistribution of power and resources. Whether it will be an upward or downward redistribution is still an open question. As John F. Kennedy once said: "In a crisis, be aware of the danger but recognize the opportunity." The capitalists know it quite well. The question is whether common people are aware of it?

\section{What Happens in North Macedonia?}

Most of the people in North Macedonia are not even informed as to the seriousness and urgency of the climate crisis. Even when they get the information, apart from environmental cycles, it does not change their attitudes or behavior. They are consumed by their everyday concerns and concentrated on the day-to-day power struggles of the establishment parties.

An additional motive for inaction is North Macedonia's objectively small contribution to the climate crisis. Due to its small population and territory its ability to produce or curb the causes of climate change are relatively minimal. However, what should be kept in mind is that this is a global struggle in which local contributions are not irrelevant, even when we are talking about small countries. What is even more relevant, however, is the fact that while local efforts contribute to the global struggle, their benefit is first and foremost local. If measures are implemented to curb air pollution in Skopje, Bitola and Tetovo, the global $\mathrm{CO}_{2}$ emissions will be reduced, but the effects will be primarily local, reducing health hazards for the inhabitants of these cities and increasing their quality of life.

Faced with increased pressure from the public to address environmental problems, the government generally responds by doing as little as possible, implementing, at best, only half-measures which do not solve the problem. Environmental protection is simply not high on their agenda. As a matter of fact, it is on the bottom.

We will take the example of forestation levels, especially because there is longitudinal data available, enabling us to draw conclusions on the actions, dedication and sense of urgency by the government. 
As can be seen from Figure 1, which covers data on forestation over the last 15 years (2004-2018), there was a peak in the period from 2008 to 2010, when the campaign "Tree Day - Plant Your Future" had started with the support of the conservative government of VMRO-DPMNE. ${ }^{10}$ Even though this campaign was terminated by the government of SDSM in 2017 (quite indicatively, only a day after the ratification of the Paris Agreement), ${ }^{11}$ the level of forestation in the years after 2011 has dropped significantly, reaching its lowest levels in 2017 and 2018.

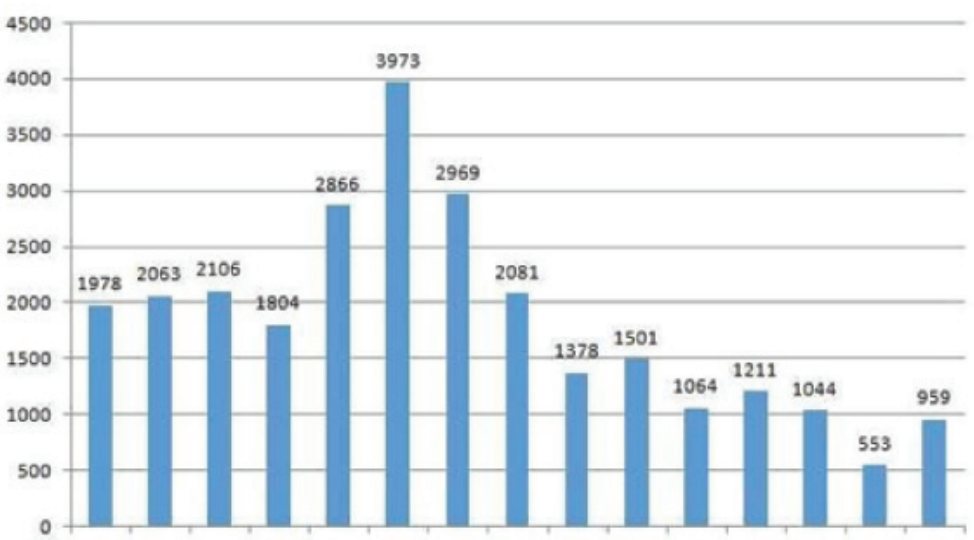

$200420052006200720082009201020112012 \quad 20132014 \quad 2015 \quad 2016 \quad 20172018$

Figure 1. Forestation in North Macedonia (2004-2018), in hectares. Source: Statistical Yearbooks of the Republic of North Macedonia (Agriculture, Forestry); MakStat

Database (Agriculture, Forestry).

When we compare these forestation levels with the ones during the socialist period, we see how extremely low the forestation levels in recent years really are. Available data since 1960 shows that the forestation levels in the last two years are not only the worst lev-

\footnotetext{
${ }^{10}$ Kole Casule, "Macedonians Plant Six Million Trees in Single Day," Reuters (November 19, 2008). https://www.reuters.com/article/us-macedonia-trees/macedonians-plant-six-milliontrees-in-single-day-idUSTRE4Al49 20081119

11 "Владата на Република Македонија ја одржа 36-тата седница: Љубомир Јовески е предлог на владата за јавен обвинител; Заради незадоволителни резултати 'Денот на дрвото' се укинува; Обезбедена е финансиска поддршка за 11 Октомври - Еурокомпозит АД Прилеп" ["The Government of Macedonia Held Its $36^{\text {th }}$ Meeting: Ljubomir Joveski Is the Government's Nominee for Chief Prosecutor. Tree Day Abandoned Due to Unsatisfactory Results; Financial Support for 11 Oktomvri - Eurokompozit Guaranteed"], Government of the Republic of Macedonia (November 7, 2017). https://vlada.mk/node/13644i "Закон за ратификација на Договорот од Париз, 6.11.2017" ["Law for Ratification of the Paris Agreement, 6.11.2017"], State Gazette of Republic of Macedonia, No. 161 (2017). http://www. slvesnik.com.mk/lssues/4b681adoc79a44d5bd4bf15098f8108e.pdf.
}

els within the last 15-year period, but the worst two years in half a century. There has not been a year with lower forestation levels in Macedonia since 1965 ! The annual forestation level in 2009, which is the highest in the whole period following the reintroduction of capitalism (i.e., since 1991), is a level that was surpassed in every single year in the 15-year period from 1975 until the fall of socialism in 1990. In 1982, the year with the highest annual level of forestation during socialism, 11,328 hectares were forested. Forestation in 2009, the year with the highest annual level of forestation during capitalism, with its 3,973 hectares, is a minuscule achievement in comparison. ${ }^{12}$ And, as can be seen from Figure 2, the total level of forestation achieved in the 28 years after the reintroduction of capitalism is still significantly lower $(64,725$ hectares) than the level of forestation achieved in the 1980 ( 76,582 hectares). This makes forestation one of the many areas where the achievements accomplished under capitalism in Macedonia are lower than those achieved under socialism. Other areas include: the living standards of common people, the quality of healthcare, education, culture, and the levels of corruption and criminality. Socialism in Macedonia, and in Yugoslavia more generally, has by no means delivered on its promises. However, this statement is far more true for capitalism than for socialism.

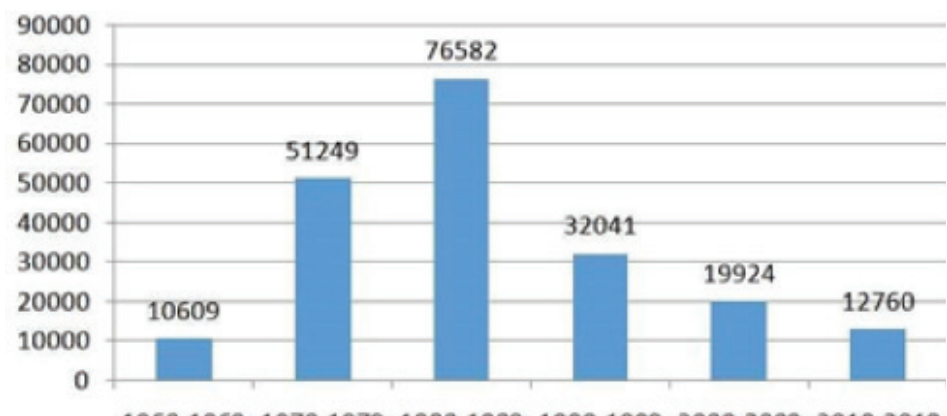

1960-1969 1970-1979 1980-1989 1990-1999 2000-2009 2010-2018

Figure 2. Forestation in North Macedonia by decades (1960-2018), in hectares. Source: Statistical Yearbooks of the Republic of North Macedonia (Agriculture, Forestry); MakStat Database (Agriculture, Forestry).

The struggle against the climate crisis has three levels. The first level requires comprehending that the climate crisis is not only a se-

${ }^{12}$ Statistical Yearbooks of the Republic of North Macedonia (Agriculture, Forestry). http://www.stat. gov.mk/PublikaciiPoOblast_en.aspx?id=34\&rbrObl=37. 
rious but an urgent problem that requires immediate action. The second level requires pressing for half-measures and implementing them on a personal level - realizing that these half-measures are a good way forward and that they have the potential to prevent climate change. And the third level requires comprehending that the half-measures, even though they represent a step forward, come too little too late, meaning that there is a pressing need to address the root of the problem.

Most of the people in North Macedonia are not even on the first level. It also takes time for most people to progress from the second level to the third, since they first need to see for themselves that half-measures promoted by the governments are not solving the problem, that some of them are implemented just to create the impression that something is being done and that their actions are lagging far behind their words. Since the climate crisis has already deepened and urgent action is needed, we clearly need to progress, as soon as possible, to the third level. Unfortunately, in countries like North Macedonia, which are lagging behind in their perception of the urgency of the climate crisis, it is not possible to progress quickly to this level. That is why informing the general public about the urgency of the climate crisis is important. It is also important to convince people to start implementing changes in their personal lives, even when it is clear from the start that these changes are miniscule. Despite being miniscule, these changes produce positive effects in a twofold manner: firstly, they overcome conservative immobility in people and, secondly, they help create awareness that something more than these personal changes should be done. Yet, the whole task cannot be limited to informing and encouraging people to implement changes in their personal habits and behaviors. The root of the problem needs to be addressed too. In other words, the work should be done on all of the aforementioned levels and not only on one of them.

\section{Attitude Change or System Change?}

Here we come to the question: What is the real root of the problem? Are individuals to blame for causing climate change and thus in need of attitude adjustments or, conversely, is the problem systemic and thus irresolvable without changing the system itself? Or maybe both changes are needed, with attitude changes enabling, deepening and making system changes more sustainable? This is far from being an academic question. As a matter of fact, it is one of the crucial questions in determining the very strategy with which to deal with the climate crisis.

One example given by Murray Bookchin can help us answer these questions. Bookchin evokes an "environmental" presentation in the 1970 in which the closing exhibit carried a startling sign which read: "The Most Dangerous Animal on Earth." It consisted simply of a huge mirror which reflected back the image of the human viewer who stood before it. Bookchin recalls a black child standing before the mirror while a white school teacher tries to explain the message which this exhibit was meant to convey. He also emphasizes that there were no exhibits of corporate boards or directors planning to deforest a mountainside or government officials acting in collusion with them.

After describing all of this, Bookchin comments:

The exhibit primarily conveyed one, basically misanthropic, message: people as such, not a rapacious society and its wealthy beneficiaries, are responsible for environmental dislocations - the poor no less than the personally wealthy, people of color no less than privileged whites, women no less than men, the oppressed no less than the oppressor. A mythical human "species" had replaced classes; individuals had replaced hierarchies; personal tastes (many of which are shaped by a predatory media) had replaced social relationships; and the disempowered who live meagre, isolated lives had replaced giant corporations, self-serving bureaucracies, and the violent paraphernalia of the State. ${ }^{13}$

It is easy to blame humans as such, as a whole or as a species, for the climate crisis. But it is also easy to understand why this standpoint (promoted by the very sector of the population that is overwhelmingly responsible for the crisis) is shallow. If humans as a whole, are

${ }^{13}$ Murray Bookchin, "Society and Ecology," Institute for Social Ecology (2019). http://social-ecology.org/wp/1993/01/society-and-ecology. 
to be blamed, if something inherent to human nature is the reason behind environmental degradation, why then do so many people act contrary to what is claimed by this theory, why do whole peoples, past and present, in the same proportion that they are unaffected by capitalism show care for nature? If we want to get to the root cause of the climate crisis, we cannot satisfy ourselves with the shallow explanation that humans as such are causing it. Our geological epoch is far from being Anthropocene. It is Capitalocene. ${ }^{14}$ And, since too many years were wasted avoiding implementing meaningful changes, the space for Green Capitalism has already closed. Drastic measures are required to deal with the climate crisis, drastic measures that presuppose system change in order to avoid climate change. It will be Socialism or Barbarism. This choice is even more pressing and deep now than a century ago, when Rosa Luxemburg proclaimed it. ${ }^{15}$

\section{What Is the Problem with Capitalism?}

So, what is the problem with Capitalism, why is this system problematic, why does it need to be overcome in order to avoid the unimaginable environmental and societal consequences of climate change? It is the practices and values that Capitalism produces and reproduces, which lead not to solutions but to the deepening of the climate crisis. And because it is so, Capitalism should not be left undisturbed, but needs to be restrained or even abolished.

In order to understand why this is so, we should remind ourselves of what Capitalism is as a social and economic system. As every successful and long-lasting social and economic system, Capitalism is not just a mode of production, it does not only determine how the economy functions, but it also produces a kind of society, in which its values are dominant. When a system ceases to be only an economy and becomes a society, then it becomes deeply rooted and cannot be overthrown easily. And Capitalism has succeeded to become such a system.

${ }_{14}$ Jason W. Moore (Ed.), Anthropocene or Capitalocene? Nature, History, and the Crisis of Capitalism (Oakland, California: PM Press, 2016).

${ }^{15}$ More correctly, she has renewed it. See lan Angus, "The Origin of Rosa Luxemburg's Slogan 'Socialism or Barbarism,"' Climate and Capitalism (October 22, 2014). https://climateandcapitalism.com/2014/10/22/origin-rosa-luxemburgs-slogan-socialism-barbarism.

\subsection{Capitalist Economy}

What characterizes a capitalist economy, what makes it different from other kinds of economies, is that production is done for profit. The goal of production is not to produce goods because of their use-value. Instead, goods are produced in order to extract profit through their production and sale, through their exchange-value. All that is produced is produced because its production brings profit, and not because there is a need for it. For sure, goods need to have some utility in order to be sold (or to possess perceived utility), but the reason why they are produced is not their utility but the extraction of profit through their production and sale. And the leitmotif is to extract as much profit as possible with as little investment as possible.

With profit on their minds, capitalists are approaching production with quite different goals in mind than independent producers who own their means of production. When independent producers trade their own products, a commodity $(C)$ is sold for money $(M)$, which buys another, different commodity with approximately equal value (C-M-C). The goal here is to produce surplus goods in order to get access to other commodities which the person does not produce. The goal of the capitalist, on the other hand, is to gain profit. In order to do this s/he invests money to buy means of production, labor power and raw materials. Through the process of production $(P)$, a commodity of more value is produced which is then sold on the market, bringing even more money to the capitalist (M-C...P...- $\mathrm{C}^{\prime}$ $\left.\mathrm{M}^{\prime}\right) .{ }^{16}$ In this process, buying cheaper labor and cheaper raw materials brings higher profits. The maximization of profit requires paying workers as little as possible and acquiring raw materials at the cheapest possible price, no matter the working conditions or environmental impact. This method of profit maximization is pursued by the capitalists not only because of pure greed but in order for them to "survive" on the market, in order to remain "competitive." As such, profit maximization is a systemic feature of capitalism and not something pursued by some individual, greedy capitalists.

Production for profit presupposes instrumentalization, seeing everything (people, nature) through the lens of profit extraction. Profit

${ }^{16}$ Karl Marx, Capital, Vol. 1, Ch. 4. Marxists.org (1999). https://www.marxists.org/archive/marx/ works/1867-c1/cho4.htm; Karl Marx, Capital, Vol. 2, Ch. 1. Marxists.org (1997). https://www. marxists.org/archive/marx/works/1885-c2/cho1.htm. 
over people and profit over nature - this is the rulebook of capitalism. "Seizing the opportunity" also means focusing on the shortterm and disregarding the long-term consequences, not only with regard to environmental devastation, but also as it concerns the future downfall of profit margins. Emptying the oceans of whales is a good example. Whales were hunted on such a large scale that it was clearly in the whaling industry's best interest to limit the accelerating predation of whales. However, the competitive dynamics of capitalism make conservation nearly impossible and the industry simply could not restrain itself. Several species of whale have already gone entirely extinct because of whaling, while others have been reduced to such an extent that they are too rare to be worth hunting. The International Whaling Commission banned commercial whaling in 1986. One of the reasons for the ban was that the number of great whales were reduced so drastically that it was no longer commercially lucrative to hunt them. ${ }^{17}$ The impossibility of even considering long-term profits (not to mention other issues!) is a feature ingrained within capitalism: due to its chaotic character, if some individual capitalist(s) tried to see beyond the short-term and limit their hunting of whales, what they would witness is other capitalists profiting from their "mistake"; meanwhile the whales would continue being hunted on the same scale. The intrinsic logic of capitalism demands focusing on the short run. Extract as much profit as possible and, when there are no profits left to extract, move the capital to another, more "profitable" industry. Capitalism has predatory features. You enter, extract profit and move along. What you leave behind is not your concern.

The externalization of costs ${ }^{18}$ is another powerful tool of capitalism. Every production has its economic and environmental costs. If the environmental cost is not included in the price of the product, it becomes cheaper. Thus, more products can be sold, increasing the profit. Take, for example, plastic bags. Their production on the large scale makes single plastic bags so cheap that sellers give them away for free. Yet, plastic bags have a huge environmental impact. If this is taken into account, it would increase the cost of producing plastic

${ }^{17}$ Ashley Dawson, Extinction: A Radical History (New York: OR Books, 2016), 43-45; Franz J. Broswimmer, Ecocide: A Short History of the Mass Extinction of Species (New York: Pluto, 2002), 67-69. ${ }^{18}$ R. Budny and R. Winfree, "Some Simple Arguments about Cost Externalization and its Relevance to the Price of Fusion Energy," Office of Scientific and Technical Information (September 27, 1999). https://www.osti.gov/servlets/purl/12125-3/47Lq/webviewable. bags, thus negatively affecting profits. But, as long as the possibility of externalizing the cost is there, it will be utilized by the capitalists in their efforts to maximize profits. Until now, environmental costs could be ignored in most cases. However, with the climate crisis looming, this can no longer be the case.

All of these negative impacts of capitalism are augmented by globalization. The celebrated freedom of the movement of capital, unleashed by globalization, has enabled capital to enter those countries (markets) where labor and environmental standards (or the lack thereof) promise the largest profits and to exit them, as easily as possible, whenever crisis looms or a new government is formed with less "business friendly" policies. Globalization has unleashed a global "race to the bottom," pressuring countries in the global south into a cutthroat competition for investments, providing foreign capital with ever lower labor and environmental standards. ${ }^{19}$

Where is the state in all of this? Surely the state can establish some sort of restraints on capitalism. But, as long as we talk about the capitalist state, these restraints are not endangering in any meaningful sense the way capitalism functions. And these restraints, following the big push of market fundamentalism in the 1970s, have become even weaker than before. Laissez-faire capitalism and market fundamentalism have brought lower taxes, deregulation and privatization. Regulated capitalism during the welfare state phase has been dismantled. Free market capitalism has regained its previous position. The state, the supposed Leviathan, had to retreat in order for the market, the real Leviathan, to have as much free reign as possible. State action has been delegitimized. Under ideological dominance of the extreme center, ${ }^{20}$ the state became shy, ${ }_{1}^{21}$ weary of interfering with the market. In some countries, the state has remained brutal in its dealings with political opposition, but in dealing with market failures, the neoliberal state has willingly abdicated from its powers. With the climate crisis in mind, as Naomi Klein emphasizes, the triumph of neo-liberalism could not have come at a worse moment. It came at a time when tackling climate change

${ }^{19}$ Jason Hickel, The Divide: A Brief Guide to Global Inequality and Its Solutions (London: Penguin Random House, 2017).

${ }^{20}$ Tariq Ali, The Extreme Centre: A Warning (London and New York: Verso 2015).

${ }^{21}$ Philippe Séguin, En attendant l'emploi (Paris: Seuil, 1996). Macedonian edition: Филип Сеген, Есеј за кризата (Скопје: Култура, 1997), 136. 
demanded collective action and increased regulation, the reverse of what market fundamentalism insists. ${ }^{22}$

\subsection{Capitalism's System of Values}

Capitalism functions against the interests of the majority, but the majority is (still) not against Capitalism. One of the major factors contributing to this paradox is capitalism's capacity to successfully legitimize itself, to be perceived as a system without alternatives, as a lesser evil and/or a system that more or less provides an acceptable life for the people, even if it functions, in the last instance, against their interests. As mentioned previously, Capitalism is not only a kind of economy but a kind of society too. It has achieved hegemony over ideas and values, nurturing people and internalizing its values among the losers and beneficiaries of the system alike. And as long as it is so, capitalism as a system cannot be questioned seriously. Overcoming the ideological hegemony of capitalism is a sine qua non of abolishing Capitalism.

What are the values that Capitalism seeks to internalize among people and the values that enable its stabilization and legitimation?

First of all, Capitalism seeks to establish a system of values which attributes worth according to the monetized value of things. What is considered valuable is what costs a lot of money and what is not monetized - is worthless. The plastic bag received free of charge is perceived as worthless and, in most cases, is thrown away immediately after its first usage - often directly onto the streets. Throwing away plastic bags does not mean that they magically disappear. It has environmental consequences, affecting many people, including those who throw the bags away in the first place. But people who throw away bags do not bother to think about that. The economic cost of the plastic bags is for them, as consumers, zero or extremely marginal. If a thing costs money, it has value, proportional to its monetary value. If it does not cost anything, it is worthless.

Ignoring the environmental cost becomes even easier through the internalization of egoistic ethics and the legitimation of egoism, which is also in line with Capitalism. It breaks solidarity and compas-

${ }^{22}$ Oliver Tickell, "Naomi Klein: A Crisis This Big Changes Everything," Ecologist (January 21, 2015). https://theecologist.org/2015/jan/21/naomi-klein-crisis-big-changes-everything. sion. Every person for himself! If $s /$ he is capable, s/he will succeed. If $s /$ he is industrious, s/he will succeed. And $s /$ he will enjoy the fruits from her/his capabilities and laboriousness. Additionally, every person has the legitimate right to do whatever s/he wants with her/ his money, provided that they are legally obtained. Does s/he have enough money to travel by plane, to buy an expensive car, to eat meat freely? No one should force her/him not to spend the money as s/he wants. When capitalist values are successfully internalized in a society, every effort to limit this kind of things is perceived as an intrusion into personal liberties, with totalitarian motives.

And what about taking responsibility for your actions, especially on issues which concern everyone? Capitalism nurtures a culture of irresponsibility, a culture of transferring the burden of responsibility onto others. This culture is strengthened in Capitalism through several factors. The first one is the already mentioned egoism. The egoistic logic is to take the benefits for yourself and to transfer as many responsibilities for your actions onto others. Then, there is instrumentalization. Everything (other people, nature) is viewed through the lens of personal gain. When it is so, the effects of our actions are something "externalized," something that someone else should deal with it. Here too, the chaotic character of Capitalism comes into play. There are a lot of actors partially contributing to the creation of the problem. The damage inflicted by everyone her/himself is small, but the damage which is aggregately done cannot be easily dismissed. In such cases, it is easy to put the blame on others. On the other hand, it is difficult to implement solutions, especially when the actions taken by the state are delegitimized in advance by market fundamentalism. Yet another factor is the direct disempowerment of the people. When democracy de facto excludes people from the decision-making process, when there is widespread perception that the people does not influence policies in any meaningful way, people lose their sense of responsibility, auto-determining that their actions are meaningless. This culture of transferring responsibility onto others is the same among the common people and the capitalists alike. When a common person uses her/his car as their main mode of transportation, s/he transfers the blame and responsibility for pollution onto others. The same is true with capitalists. When a construction capitalist bribes politicians in order to build some ed- 
ifice, her/his action can contribute to pollution by preventing wind from dispersing polluted air away from the city. However, the building of a single additional edifice contributes only marginally to this problem. And, as such, it is easy for the construction capitalist to put the blame onto others and exclude her/himself from any responsibility. What should be kept in mind here is that, even though common people and capitalists draw the same conclusion from the capitalist system of values, the effects of the behavior driven by this system of values is much greater in the case of capitalists than in the case of common people.

Lastly, but maybe most importantly, the capitalist system of valves stimulates consumerism. The increased consumption of goods stimulates an increase in production through which capitalists receive increased profits. The negative feature of this plan is that consumption, if left alone, can easily reach levels of oversaturation, at which point both production and profits drop. To avoid such scenarios, various marketing strategies are increasingly implemented; goods are produced to be easily spoiled and consumers are sensibilized to yearn for newer and ever better versions of their products. In order for the capitalism to function smoothly, the system needs not only consumers but consumerists as well - people who dance in accordance with capitalist tunes. Consumerism is not only a part of capitalist culture; it is a sine qua non of the capitalist economy and society. Through consumerism, many people above the poverty line, get their small piece of Capitalism. A good indication of how well the consumerist ethos is ingrained in people, is their instant accusation of asceticism whenever consumerism is criticized. For sure, consumerism can be criticized from ascetic positions. However, not every criticism of consumerism is made from ascetic positions. Between the extremes of consumerism and asceticism lies a huge space, which can be identified neither as consumerism nor as asceticism. But for the well sensibilized consumerist everything that is not pure consumerism is automatically asceticism.

\section{The Way Forward}

The climate crisis is entering its final phase. It has become clear that modest, non-systemic changes are, to a large extent, no longer options. The time during which it was possible to implement Green
Capitalism has already passed. All efforts to introduce it have come against the wall of capitalist logic. It is now clear, as Klein has put it, that

our economic system and our planetary system are at war. What the climate needs to avoid collapse is a contraction in humanity's use of resources; what our economic model demands to avoid collapse is unfettered expansion. Only one of these sets of rules can be changed, and it's not the laws of nature. ${ }^{23}$

At the present moment, there are no non-radical options left. ${ }^{24} \mathrm{Ei}$ ther we will destroy Capitalism or Capitalism will destroy us.

Of course, understanding that Capitalism is the problem represents a huge step forward for many people who are not accustomed to questioning capitalist hegemony. Fighting Capitalism itself is an even bigger step forward. But the climate crisis is not something that can be ignored indefinitely. As a matter of fact, it will soon force its urgency upon us. In such times, new, unorthodox thinking is required. It is good here to remind ourselves of the words of Jawaharlal Nehru: "Most of us seldom take the trouble to think. It is a troublesome and fatiguing process and often leads to uncomfortable conclusions. But crises and deadlocks when they occur have at least this advantage that they force us to think." 25

The new paradigm of thinking - appropriate for the upcoming turbulent times - will require modernizing and integrating the "red" and "green" discourses. The red should be made greener, and the green should be made redder. The red forces should notice that for the first time since World War Two, Capitalism is being seriously questioned, that, because it is leading most of humanity towards disaster and is incapable of internally thwarting the climate crisis through its own functioning - it is quite clearly historically overcome system. But the masses cannot be convinced that it is so by repeating many of the old formulas and strategies. Socialism is the only real alternative in the face of the climate crisis, but only as Green Socialism. And the

\footnotetext{
${ }^{23}$ Naomi Klein, This Changes Everything (London: Penguin Books, 2015), 21.

${ }^{24}$ Tickell, "A Crisis."

25 Jawaharlal Nehru, The Unity of India: Collected Writings, 1937-1940 (New York: The John Day Company, 1942), 94.
} 
Reds should not treat their ideologies as relics to be religiously cherished but as tools to help them better understand and explain their reality. On the other hand, the Greens should remind themselves of their red roots, forgotten in their shift towards the center of the political spectrum. They should acknowledge that nearly all ecological problems are social problems, ${ }^{26}$ that pushing only for the green agenda (without red features) will alienate the poor who often feel threatened by it and, most importantly, should acknowledge that climate change demands nothing short of system change. In this process of mitigating and overcoming the climate crisis the Reds and the Greens can learn a lot from each other and can become the force that can prevent humanity from slipping into barbarity and unimaginable suffering.

Within this general battle strategy, people must pressure the state into enacting policy changes across many fields as well as implementing of changes in their own personal behavior. The latter should not be underestimated. People can and should use more public transportation and bikes; should eat less meat and tend towards more vegetarian and vegan diets; should stop throwing away food; should reduce the usage of energy and water in their households; should reduce their own production of plastic waste; should sort their trash; should stop smoking, etc. Finally, they should reject the ideology of consumerism. Even though these changes can seem too big on a personal level, they are, clearly, very small contributions overall. Still, these measures have two important effects on the people who have started to implement them. Firstly, these people start to understand that something more than individual actions are needed in order to overcome the climate crisis and that changes should be implemented not only in consumption but in production too. Secondly, through the implementation of these measures, persons overcome their capitalist socialization. For example, if a person who has enough economic means to drive her/his car as much as s/he wants, still chooses to use a bike (due to the environmental costs of using a personal vehicle), s/he contributes marginally to the reduction of air pollution, but, more importantly, s/he exits the capitalist logic.

In these historic times we should not succumb to apathy and lethargy. We are the last generation that can still make a real difference.

${ }^{26}$ Bookchin, "Society and Ecology."
We have power both as citizens and as consumers, both individually and (far more importantly) collectively. The climate crisis is not only a serious but an urgent problem. We all know the fable about the boiled frog. If you put a frog into a pot of boiling water, it will leap out right away to escape the danger. But, if you put a frog in a kettle that is filled with water that is cool and pleasant, and then gradually heat the kettle until it starts boiling, the frog will not become aware of the threat until it is too late. Let us hope that Homo Sapiens, the Wise Humans, will have enough wisdom to understand the existential threat that s/he is facing and that s/he will act accordingly. If not, it will be the greatest tragicomedy in the history of humanity: the species that is so proud of its intelligence will react as a simple frog, becoming aware of the threat to its life when it is already too late.

As United Nations Secretary-General António Guterres said during this year's Climate Action Summit: "The climate emergency is a race we are losing, but it is a race we can win. ${ }^{27}$ In this moment, when we are running a race which we are losing but which is still possible to win, Gramsci's approach can serve us the best. We need pessimism of the intellect, but optimism of the will. Hopefully, our actions will not only overcome the climate crisis but finally bring about a much better world than the present one.
${ }_{27}$ Climate Action Summit 2019, United Nations (September 23, 2019). https://www.un.org/en/ climatechange/assets/pdf/CAS_main_release.pdf. 